\title{
DESAFÍOS OCUPACIONALES DE LOS ROLES FEMENINOS EN TIEMPOS DE PANDEMIA
}

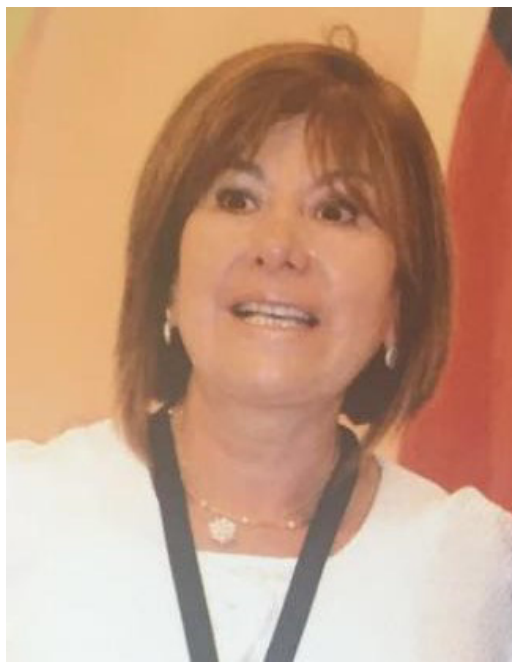

\footnotetext{
$\mathrm{E}$
} Modelo Patriarcal ha impactado diversas culturas y sociedades y desafortunadamente sigue imperando en la actualidad en el mundo occidental. La emergencia de la pandemia y el consecuente confinamiento exacerbó dichos sesgos sociales, otorgándole especialmente a la mujer exigencias de diferente naturaleza asociados al rol de género desde una perspectiva patriarcal, debiendo ocuparse de las tareas domésticas, de la crianza, apoyo educativo, cuidado de personas mayores o personas con un alto nivel de dependencia y finalmente el desempeño laboral. Todo esto tiene ocurrencia en un territorio no pocas veces precario, con escaso acceso a la tecnología y donde deben converger temporalmente todos los miembros involucrados. Eso inevitablemente ha redundado en fricciones interpersonales, devaluaciones, críticas y lamentablemente en aumento de la tasa de femicidios. En la actualidad se registran 14 femicidios consumados y 46 frustrados (Servicio Nacional de la Mujer y la Equidad de Género, 2021), lo que demuestra la precarización de políticas públicas, excesiva burocracia y escasas redes apoyo y de seguridad social que resguarden los derechos e intereses de mujeres a nivel nacional.

Los roles extremadamente dicotómicos del Modelo Patriarcal, esto es, "el hombre validado desde la provisión de alimentos y la potestad en la toma de decisiones" ha llevado a una suerte de auto complacencia societaria y a la perpetuación en la asignación de cargos de mayor rango a los hombres, con el consecuente mayor nivel de ingresos. Desafortunadamente dicha conducta no hace más que crear un círculo vicioso, ya que dicha posición les otorga nuevamente mayor potestad.

La mujer en tanto, cuyos roles asignados desde este Modelo estaba mandatada al cuidado de la prole y al soporte afectivo, se ha visto particularmente vulnerada cuando debe además responder a exigencias de un trabajo asalariado. La inclusión a un trabajo remunerado 
fuera del hogar provee además del recurso económico, sentimiento de pertenencia y autoeficacia personal. Despojada temporalmente de éste debido a la reclusión domiciliaria, ha debido quedar a cargo de gran parte de las tareas domésticas con la estigmatización y devaluación que socialmente se les ha otorgado a dichas labores.

La literatura ha señalado extensamente los roles de cuidado a los que se ven sometidas especialmente las mujeres. Así, durante las etapas del ciclo vital o tránsito de vida, la mujer es quien debe proveer cuidados a los hijas e hijos en la adultez temprana, a los nietos en la adultez media y no pocas veces al cónyuge y /o a los padres y madres durante la adultez tardía, considerando también que nos vamos haciendo cada vez más longevos.

Diversos artículos logran abordar, desde la perspectiva de la mujer, como éstas han llegado a desarrollar labores de cuidado, casi de forma inconsciente al observar cómo sus antecesoras han asumido dicho proceso. Desde esta visión crítica, Lagarde (2013) plantea que el cuidado se desarrolla porque "las sociedades actuales, como muchas del pasado, fragmentan el cuidado y lo asignan como condición natural a partir de las organizaciones sociales: la de género, la de clase, la étnica, la nacional y la regional/local", tal como ocurre en nuestro país, en donde las brechas sociales, económicas y educativas aún son significativas al no considerar a la mujer dentro de planes y políticas publicas que fomenten la igualdad y equidad en el acceso a bienes esenciales y naturales.

Esto implica altos montos de stress y de desgaste emocional si pensamos que el cuidado es una tarea de sostenimiento permanente desde diferentes ámbitos: ayuda material y provisión de servicios, guía y consejo, apoyo afectivo, compañía social y otros.

La Terapia Ocupacional plantea áreas de desempeño ocupacional y es deber de nuestra disciplina, promoverlas de manera de obtener el máximo de funcionalidad otorgándole a la persona un sentido de valoración personal. Estas áreas son: Actividades de la vida diaria (básicas e instrumentales), en donde actividades como higiene y arreglo personal, y alimentación pasan a segundo plano al tener que priorizar las necesidades de la persona a cuidar / Actividades Productivas/ Actividades de Participación Social/ en donde el hecho de no poder socializar y tener redes de apoyo, ya sea para la recreación o compartir experiencias similares, genera mucha angustia, afectando sensitivamente su salud mental / Actividades de esparcimiento y tiempo libre/ Descanso y Sueño. Por esto no es difícil comprender que la casi totalidad de estas actividades se hayan visto mermadas en la mujer producto de la pandemia ya que debe enfrentarse a diario al cumplimiento satisfactorio de las necesidades de otros.

No pocas veces emerge un sentimiento de culpabilidad si la exigencia la sobrepasa o solo puede dar respuesta parcial o insatisfactoria a los requerimientos. Se ha planteado que una estrategia adaptativa es la auto indulgencia, tarea nada fácil en las culturas occidentales en que está arraigado el sentido de éxito y competencia personal por sobre la sabiduría de privilegiar el presente inmediato.

No podemos dejar de mencionar que el Departamento de Terapia Ocupacional y Ciencia de la Ocupación, cuenta entre sus más destacadas académicas a la Terapeuta Ocupacional Paula Soto, Directora de Igualdad de Género quien lidera un grupo humano ocupado de establecer lineamientos que respete los derechos tantas veces vulnerados de todas las 
personas ya sea por su género u orientación sexual, promoviendo la equidad y acompañando en procesos de "discriminación arbitraria, acoso y violencia en todas sus formas, que afecten a las personas que conforman la comunidad de la Facultad de Medicina" (Dirección de Igualdad de Género, 2021).

\section{Referencias Bibliográficas}

Lagarde, M. (2013). Mujeres cuidadoras: Entre la obligación y la satisfacción. Encuentro Anual Sare: Cuidar cuesta: Costes y beneficios del cuidado. Emakunde.

Servicio Nacional de la Mujer y la Equidad de Género (2021). Femicidio. https://www.sernameg.gob.cl/?page id=27084\#: : :text=Seg\%C3\%BAn\%20la\%20legislaci\%C3\%B3n\%20chilena\%20(Ley, sentimental\%20 o\%20sexual\%20sin\%20 convivencia.

Facultad de Medicina Universidad de Chile. (2021). Dirección de Igualdad de Género. http://www.medicina. uchile.cl/facultad/estructura/organismos-de-asesoria/direccion-de-igualdad-de-genero

\section{Angelica Montenegro M.}

Terapeuta Ocupacional Jefe Depto.de Psiquiatria y Salud Mental HCUCH Profesor Adjunto. Depto. de T O y Ciencia de la Ocupación. Universidad de Chile 